\title{
ESTIMATIVA TEÓRICO DA PRODUÇÃO DE METANO NO ATERRO SANITÁRIO DE VITORIA DA CONQUISTA - BA
}

Welder Cardoso Oliveira - welder.cardosooliveira@ gmail.com

Instituto Federal da Bahia - campus Vitória da Conquista 


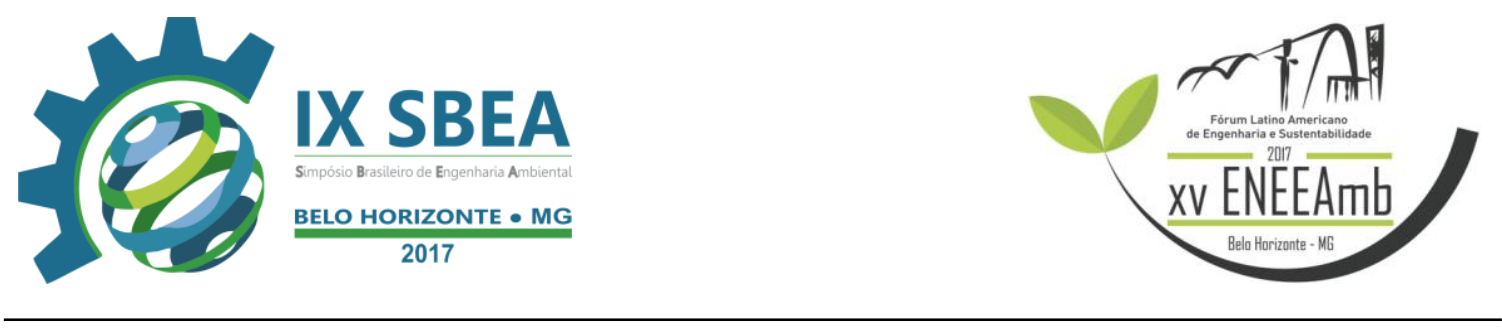

\section{RESUMO}

A grande capacidade, atual de consumo e produção dos indivíduos tem provocado o aumento acelerado da geração de resíduos sólidos. Enquanto existe por meio da administração pública a incapacidade de ações corretas para o manejo de resíduos aliado ao elevado custo financeiro para que ocorra o correto gerenciamento, são essas algumas das maiores dificuldades encontradas para o setor. Uma das soluções para o processo de disposição final dos resíduos sólidos urbanos são os aterros sanitários. A decomposição anaeróbia da matéria orgânica produz a liberação do biogás, cujos principais constituintes são o metano e dióxido de carbono. A partir de uma estimativa teórica que leva em consideração a quantidade de resíduos gerados em um dado período de tempo, a relação de componentes dos resíduos sólidos, o inicio de deposição e o ano atual para o qual se pretende estimar a geração de metano e demais variáveis chegou-se ao valor estimado de metano gerado no Aterro Sanitário de Vitoria da Conquista - BA.

Palavras-chave: Resíduos Sólidos, Aterro Sanitário, Biogás.

\section{INTRODUÇÃO/OBJETIVO}

Moraes (1998), estudando os impactos dos resíduos sólidos domiciliares urbanos na saúde, sugere que o tipo de acondicionamento domiciliar e a prestação do serviço de coleta contribuíram para controlar a transmissão das doenças diarreicas e parasitárias. Desse modo, a universalização do serviço regular de coleta de resíduos sólidos domiciliares urbanos, e também a mudança de comportamento das pessoas no que tange a destinação dos resíduos sólidos, são medidas que contribuem para a redução dos fatores de riscos ambientais. No Brasil, grande parte dos resíduos sólidos ainda é descartada sem nenhuma forma de tratamento. Espaços de despejos clandestinos estão presentes na maioria dos municípios e os aterros verdadeiramente sanitários são poucos. Além dos diversos impactos ambientais locais, sobre a saúde e qualidade de vida dos cidadãos, os resíduos sólidos urbanos sem disposição adequada consistem em uma fonte significativa das emissões de metano (CH4) (ICLEI, 2009, p. 7). É preciso entender que o manejo dos resíduos sólidos está contido na definição de saneamento básico, assim especificando a cidade de Vitoria da Conquista, Moraes diz: 


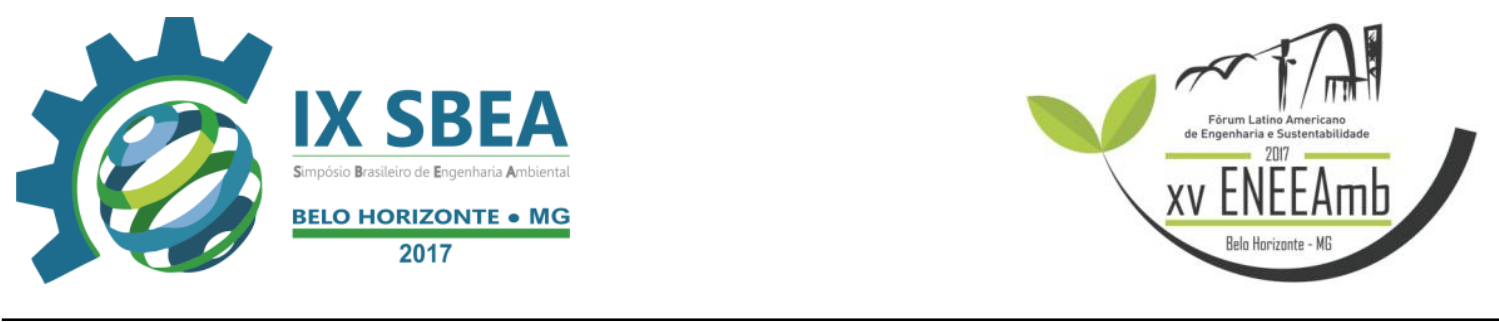

"O Plano de Saneamento Ambiental para Vitória da Conquista, propriamente dito, contendo os princípios, as diretrizes, as metas e a proposta de um Sistema Municipal de Saneamento Ambiental, envolvendo as componentes abastecimento de água, esgotamento sanitário, manejo de águas pluviais e de resíduos sólidos. " (MORAES et al., 1999a).

A definição para resíduos sólidos é dada na Política Nacional de Resíduos Sólidos (PRNS) que considera resíduo sólido como:

“(...)qualquer material, substância, objeto ou bem descartado, oriundo de atividades humanas em sociedade, cuja destinação final se procede, se propõe a proceder ou se está obrigado a proceder, nos estados sólido ou semissólido, bem como gases contidos em recipientes e líquidos cujas particularidades tornem inviável o seu lançamento na rede pública de esgoto ou em corpos d'agua, ou exijam para isso soluções técnicas ou economicamente inviáveis em face da melhor tecnologia possível." (BRASIL, 2010).

A quantidade e composição dos resíduos variam de acordo com a população, seus diferentes extratos sociais, economia e grau de urbanização (PRANDINI, JARDIM e D’ALMEIDA, 1995). A caracterização dos Resíduos Sólidos Urbanos (RSU) gerados por um município é fundamental para qualquer definição posterior de gerenciamento, quantidade e qualidade, tendências futuras, cálculo da capacidade e tipo de equipamento de coleta, tratamento e destinação final (LIMA, 2004).

Para Machado (2013), as formas mais conhecidas de disposição final de resíduos são o aterro sanitário, aterro controlado e lixão a céu aberto. No Brasil, 58,4\% dos resíduos sólidos urbanos produzidos em 2014 tiveram destinação adequada, sendo encaminhados para aterros sanitários, enquanto que $24,2 \%$ foram para aterros controlados e 17,4\% para lixões. De acordo com a Associação Brasileira de Empresas de Limpeza Pública e Resíduos Especiais (ABRELPE), em 2014, de 5.570 municípios brasileiros, 2.236 destinam seus RSU para aterro sanitário, 1.775 para aterros controlados e 1.559 para lixões.

Segundo Silva (2013), a melhor forma de destinação final dos resíduos sólidos urbanos é a disposição em aterros sanitários. Nesse contexto, a adoção da PNRS, então, estabeleceu uma meta ambiciosa e desafiadora em seu Artigo 54, o qual dava o prazo de quatro anos para que os municípios façam a disposição final ambientalmente adequada dos rejeitos, ou seja, propunha o fim dos lixões até meados de 2014. 


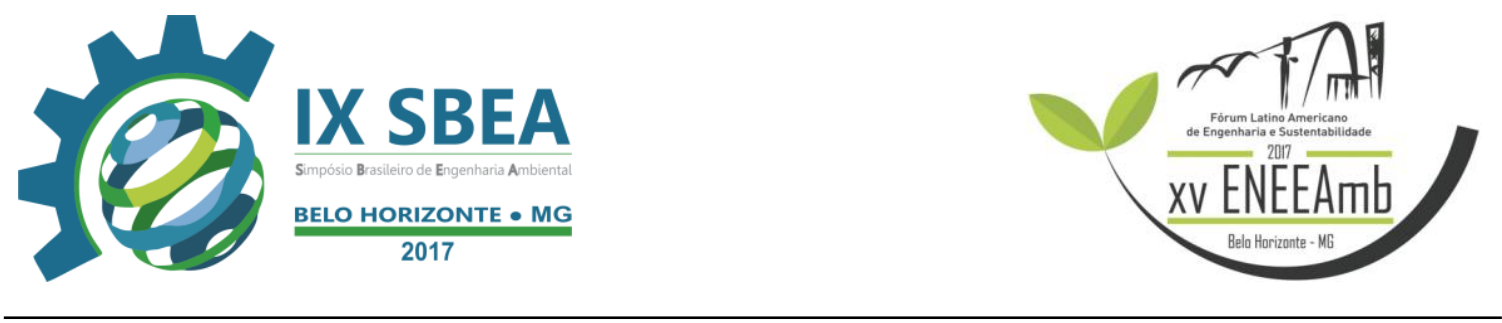

O processo de biodegradação dos resíduos sólidos urbanos no interior do aterro sanitário produz gases tóxicos, que além de prejudicar a saúde humana provocam impactos para o meio ambiente. Os principais gases gerados durante esse processo são dióxido de carbono $(\mathrm{CO} 2)$ representado por aproximadamente $45 \%$, metano $(\mathrm{CH} 4)$ contribuindo com 60\%, gás sulfídrico $(\mathrm{H} 2 \mathrm{~S})$, mercaptanas dentre outros. Ao conjunto desses gases dá-se o nome de biogás. Esses gases são preocupantes do ponto de vista local (odores e efeitos sobre a saúde), regional e global (o metano contribui para o aumento do efeito estufa). A produção de metano em aterros municipais em todo o mundo representa de 5 a $15 \%$ do metano total lançado na atmosfera. Além disso, o metano é de 20 a 25 vezes mais efetivo que o CO2 na absorção da energia infravermelha, contribuindo significativamente para o aumento do efeito estufa (CATAPRETA; SIMÕES, 2009).

Tendo em vista que a maior parte do biogás é formado de metano $(\mathrm{CH} 4)$ além de existir a necessidade de estudos sobre o tema para a cidade de Vitoria da Conquista que conta com um aterro sanitário, e sendo possível agregar informações para a possível instalação de equipamentos que promovam a queima do biogás gerado, o presente trabalho visa estimar a quantidade de metano gerado no aterro sanitário da cidade de Vitoria da Conquista para que, futuramente seja possível a realização da queima ou beneficiamento do mesmo, uma vez que o biogás gerado em aterro sanitário possui uma vasta gama de utilização energética. presentar a fundamentação destacando a importância/relevância e os objetivos do trabalho. O trabalho aceito estará sujeito a revisões por parte de seus autores, para a sua aceitação final e inclusão nos Anais conforme parecer da Comissão Científica do evento.

\section{METODOLOGIA}

\subsection{Localização da área de estudo}

O Aterro Sanitário de Vitoria da Conquista está localizado na área urbana do município, na parte oeste do mesmo, distante aproximadamente $10 \mathrm{~km}$ do centro da cidade, no Bairro de Zabelê. 


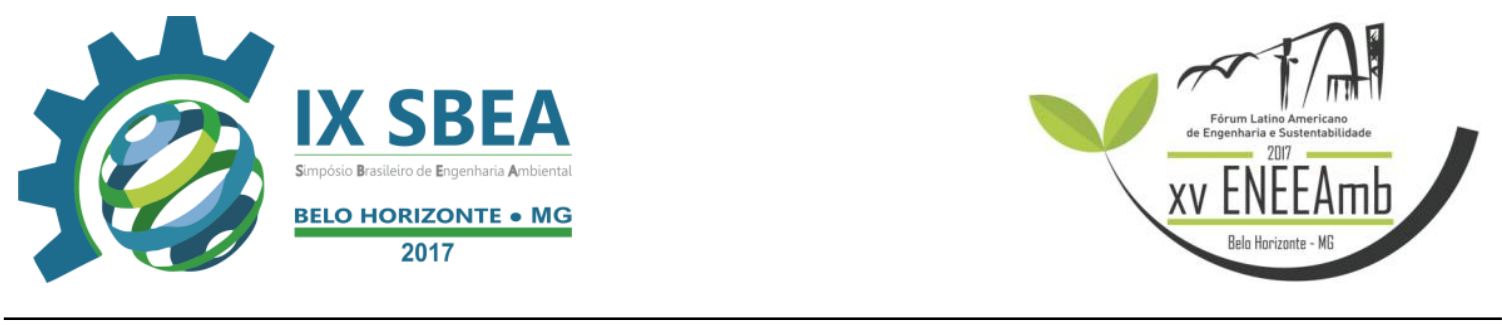

3.2 A projeção da geração de resíduos sólidos urbanos (RSU) no aterro de Vitoria da Conquista

Para tal projeção utilizamos como modelo matemático para o crescimento populacional e projeção da população para um determinado período, o cálculo de crescimento logístico.

$$
\begin{gathered}
\mathrm{P}_{\mathrm{t}}=\frac{\mathrm{P}_{\mathrm{s}}}{1+\mathrm{c} * \mathrm{e}^{\mathrm{K}_{1} *\left(\mathrm{t}-\mathrm{t}_{0}\right)},} \\
\mathrm{P}_{\mathrm{S}}=\frac{2 \mathrm{P}_{0} * \mathrm{P}_{1} * \mathrm{P}_{2}-\mathrm{P}_{1}{ }^{2} *\left(\mathrm{P}_{0}+\mathrm{P}_{2}\right)}{\mathrm{P}_{0} * \mathrm{P}_{2}-\mathrm{P}_{1}^{2}} \\
\mathrm{~K}_{1}=\frac{1}{\mathrm{t}_{2}-\mathrm{t}_{1}} * \ln \left[\frac{\mathrm{P}_{0} *\left(\mathrm{P}_{\mathrm{S}}-\mathrm{P}_{1}\right)}{\mathrm{P}_{1} *\left(\mathrm{P}_{\mathrm{s}}-\mathrm{P}_{0}\right)}\right] \\
\mathrm{c}=\frac{\left(\mathrm{P}_{\left.\mathrm{s}-\mathrm{P}_{0}\right)}\right.}{\mathrm{P}_{0}}
\end{gathered}
$$

$P_{t}-$ População no ano $t$

$\mathrm{P}_{\mathrm{S}}$ - População de Saturação

$\mathrm{K}_{1}$ - Coeficiente de crescimento

c- Coeficiente

t - Ano da Projeção

$\mathrm{t}_{0}$ - ano referente ao $\mathrm{P}_{0}$

Para o cálculo da geração per capita usamos a Fórmula (5), tendo como dados população do ano de 2016 e a geração anual de 2016, uma sendo dado do IBGE e outro do SNIS.

$$
\mathrm{GD}=\frac{\mathrm{GA}}{365}, \text { daí GPc }=\frac{\mathrm{GD}}{\text { POPULAÇ̃̃O T }}
$$


Onde:

GD = Geração Diaria

GPc $=$ Geração Percapita

$\mathrm{T}=$ População do ano

Geração percapita, adicionar 0,01 ou $1 \%$ a cada ano. Geração diária: multiplica a população anula pela de geração percapita. E a Geração anual é o produto da geração diária por 365 e a geração acumula é o somatório dos anos anteriores.

\section{3 Estimativa do potencial de geração de metano}

A metodologia proposta neste estudo utilizou um modelo teórico de estimativa como ferramenta de previsão do volume de metano a ser gerado pelo período de tempo considerado. O método utilizado foi desenvolvido pelo Painel Intergovernamental sobre Mudanças Climáticas (IPCC, 1996).

Para o cálculo do potencial de geração em aterros, utilizou-se as metodologias elaboradas pelo IPCC.

Para o cálculo da emissão de metano, utiliza-se a Equação (6):

$$
\mathrm{E}_{\mathrm{CH}_{4}}=\mathrm{k} * \mathrm{R}_{\mathrm{x}} * \mathrm{~L}_{0} * \mathrm{e}^{-\mathrm{k}(\mathrm{x}-\mathrm{T})}
$$

Onde:

$\mathrm{E}_{\mathrm{CH}_{4}}=$ Emissão de metano

$\mathrm{k}=$ Constante de decaimento;

$\mathrm{L}_{0}=$ Potencial de geração de metano;

$\mathrm{x}=$ Ano atual;

$\mathrm{T}=$ Ano de doposição do residuo no aterro;

$\mathrm{R}_{\mathrm{X}}=$ Fluxo de residuos do ano.

Será necessário primeiro calcular a fração de carbono orgânico degradável no lixo (COD) depositado no aterro utiliza-se a Equação (7): 


$$
\mathrm{COD}=\sum\left(\mathrm{COD}_{\mathrm{i}} * \mathrm{~W}_{\mathrm{i}}\right)
$$

Onde:

COD = Fração de carbono orgânico degradável no lixo;

$\mathrm{COD}_{\mathrm{i}}=$ Fração de carbono orgânico degradável no tipo de resíduo i;

$\mathrm{W}_{\mathrm{i}}=$ Fração do tipo de resíduo i por categoria do resíduo.

Após o cálculo do COD, calcula-se o potencial de geração de metano no resíduo (L0), observado na Equação 8:

$$
\mathrm{L}_{0}=\mathrm{FMC} * \mathrm{COD} * \mathrm{COD}_{\mathrm{f}} * \mathrm{~F} * \frac{16}{12}
$$

$\mathrm{F}=$ Fração de metano presente no biogás;

FMC $=$ Fator de correção do metano $=0,8$ inadequado (profundo $>5 \mathrm{~m}$ de lixo);

$\mathrm{COD}=$ Valor obtido por meio dos cálculos realizados na Equação (7);

CODf $=$ Fração altamente biodegradável no resíduo brasileiro, $\operatorname{CODf}=0,014 \mathrm{~T}+$ $0,28=0,77$, onde $\mathrm{T}$ : temperatura $\left({ }^{\circ} \mathrm{C}\right)$ na zona anaeróbia dos resíduos, estimada em $35^{\circ} \mathrm{C}$;

F = Fração de metano presente no biogás.

Caso o aterro não possua o valor real da quantidade de metano presente no biogás, pode-se utilizar a estimativa de 0,5 , pois geralmente a quantidade de metano presente no biogás de aterro é $50 \%$.

\section{RESULTADOS E DISCUSSÃO}

No Política e Plano Municipal De Saneamento Ambiental, Secretaria Nacional de Saneamento Básico lemos:

"Tomando como base a geração per capita diária de resíduos sólidos de $0,300 \mathrm{~kg} / \mathrm{hab}$.dia e o tipo de pavimento das vias, foi proposta para cada localidade a varrição manual dos resíduos, a separação dos resíduos na origem e a coleta diferenciada por meio de carroça com tração animal. Projetou-se aterro sanitário manual como solução para a disposição do rejeito dos resíduos sólidos" (PPMSA, 2010)

Utilizando as Equações (1),(2),(3),(4) e (5). Montamos o Quadro 1: 


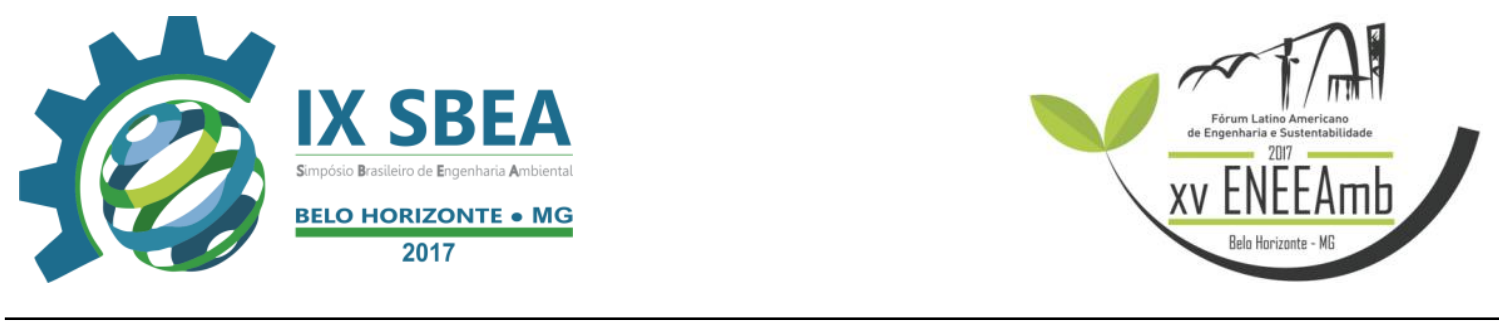

Quadro 1 - Geração de RSU e o Acumulo Anual

\begin{tabular}{|r|r|r|r|r|r|}
\hline \multicolumn{1}{|c|}{ Ano } & Habitantes & $\begin{array}{c}\text { Geração Per } \\
\text { Capita } \\
\text { (kg/hab.dia })\end{array}$ & $\begin{array}{c}\text { Geração } \\
\text { Diária (kg) }\end{array}$ & $\begin{array}{c}\text { Geração } \\
\text { Anual } \\
\text { (Toneladas) }\end{array}$ & $\begin{array}{c}\text { Geração } \\
\text { Acumulada } \\
\text { (Toneladas) }\end{array}$ \\
\hline 2016 & 346069 & 0,566 & 195972,6049 & $71.530,80$ & $71.530,80$ \\
\hline 2017 & 342301,8085 & 0,576 & 197165,8417 & 71965,53222 & $143.496,33$ \\
\hline 2018 & 346069 & 0,586 & 202796,434 & 74020,69841 & $217.517,03$ \\
\hline 2019 & 349724,1913 & 0,596 & 208435,618 & 76079,00058 & $293.596,03$ \\
\hline 2020 & 353267,6487 & 0,606 & 214080,1951 & 78139,27122 & $371.735,30$ \\
\hline 2021 & 356699,9111 & 0,616 & 219727,1452 & 80200,40801 & $451.935,71$ \\
\hline
\end{tabular}

Fonte: Autor

Constatamos então que a projeção do aterro sanitário de Vitoria da Conquista, no que tange a geração percapita de RSU tem um deficit de aproximadamente 0,250 quilogramas por habitante, aproximadamente $83 \%$ a mais do previsto no plano.

Em IPCC (1996) é apresentada uma metodologia de fácil aplicação para cálculo de emissão de metano a partir de resíduos sólidos para países ou regiões específicas. Esse método envolve a estimativa da quantidade de carbono orgânico degradável presente no lixo, calculando assim a quantidade de metano que pode ser gerada por determinada quantidade de resíduo depositado, considerando categorias de resíduos sólidos domésticos.

É preciso conhecer a composição gravimétrica, ela identifica o percentual de cada componente do resíduo em relação ao peso total da amostra analisada e permite identificar a quantidade e a qualidade dos resíduos gerados pelos municípios. Geralmente, os componentes dos resíduos sólidos urbanos estão distribuídos em matéria orgânica, papel, papelão, trapos, plástico, metais, vidro, borracha, madeira e outros.

Para calcular a emissão de metano usaremos como base os dados contidos na Tabela 3.3 do Módulo 5 - Resíduos, do Guia do IPCC, Volume 3: Disposição de 
Resíduos Sólidos, de 1996, tem-se o valor de k para clima tropical - resíduo úmido (de acordo com a composição do lixo). Então usaremos da seguinte forma: para o papel $\mathrm{k}=$ 0,07; para resíduos orgânicos $\mathrm{k}=0,17$, para madeira $\mathrm{k}=0,035$. Usando o $\mathrm{Rx}$ do ano de 2020, presente na tabela 1 e considerando que o ano de deposição do RSU 2016.

Se a fração de metano presente no biogás for $50 \%$, a quantidade de biogás será o dobro do valor de ECH4, ou seja, será duas vezes a quantidade de metano obtida na Equação (6) (ICLEI, 2009, p. 64), então temos a Tabela 1.

Tabela 1 - Comportamento da geração de gás metano e biogás

\begin{tabular}{c|c}
\multicolumn{2}{c}{$\mathrm{m}^{3} /$ Ano } \\
\hline Metano & 436,78 \\
Biogás & 873,52
\end{tabular}

Fonte: Autor

A queima do gás metano, além de ser passível de aproveitamento energético, ocasiona a redução dos gases de efeito estufa na atmosfera, uma vez que o dióxido de carbono, produto da queima, possui um potencial de aquecimento global 21 vezes menor que o metano (IPCC, 2006).

\section{CONCLUSÕES/RECOMENDAÇÕES}

O método apresentado neste trabalho é uma estimativa teórica. Vale salientar que uma melhor forma de avaliar o potencial de um aterro específico seria através da realização de pesquisas e medições de campo da quantidade de biogás e concentração presente de metano, direcionadas para implantação de um projeto específico.

A projeção da produção de biogás e do gás metano podem ser feitas através de modelos matemáticos que utilizam, basicamente, a quantidade de resíduos como parâmetro de entrada. Esta estimativa é apenas teórica e não pode ser utilizada a não ser como fonte de conhecimento prévio da quantidade de biogás que pode ser produzido por aterros sanitários. Dessa forma este trabalho poderá dar subsídio de conhecimento às autoridades competentes para a realização de projetos de aproveitamento do biogás 
do Aterro Sanitário de Vitoria da Conquista. Indicando um erro de projeção, acha visto que o índice de geração percapita de RSU tem um deficit de aproximadamente 0,250 kilogramas por habitante, aproximadamente $83 \%$ a mais do previsto no plano. Isso indica uma superlotação do aterro, e um tempo de vida que cai de forma logarítmica. Com a projeção de produção de RSU, podemos prever consequentemente a relação direta entre a produção de biogás e a quantidade de RSU produzidos durante o ano.

\section{REFERÊNCIAS BIBLIOGRÁFICAS}

BIDONE, F. R. A.; POVINELLI, J. Conceitos básicos de resíduos sólidos. São Carlos: EESC/USP, 1999. 120p

BRASIL. Lei do Resíduos Sólidos DEC.- Lei 12.305, de 02 de Agosto de 2010. Institui a Política Nacional dos Resíduos Sólidos.

CATAPRETA, C. A. A; SIMÕES, G. F. Monitoramento da qualidade do biogás gerado em um aterro sanitário experimental. In: XXV Congresso Brasileiro de Engenharia Sanitária e Ambiental, Recife-PE, 2009.

IBGE - Instituto Brasileiro de Geografia e Estatística. Disponível em: http://www.ibge.gov.br/home/presidencia/noticias/noticiavisualiza.php?idnoticia $=1691 \$ i$ dpagina=1. Acesso em: 01 de abril de 2017.

ICLEI, Manual para aproveitamento de biogás. São Paulo, 2009, 81 p. Disponível em: http://www.ipccnggip.iges.or.jp/public/gl/invs6.html. Acesso em: 01 de abril de 2017.

IPCC, Intergovernamental Panel on Climate Change. Guia para inventários nacionais de gases de efeito estufa. Módulo 6: Lixo. Volume 2: Livro de trabalho, 1996. Disponível em: http://www.ipccnggip.iges.or.jp/public/gl/invs6.htm I. Acesso em: 01 abril. 2017.

LIMA, L. M. Q. Lixo: Tratamento e Biorremediação. 3. Ed. Campinas: Hemus, 2004.

MACHADO, G. B. Aterro Sanitário. Portal dos Resíduos Sólidos, 2013. Disponível em:<http://www.portalresiduossolidos.com/aterro-sanitario/>. Acesso em: 01 abril. 2017. 
MINISTÉRIO DAS CIDADES SECRETARIA NACIONAL DE SANEAMENTO AMBIENTAL. Política e plano municipal de saneamento ambiental - Experiências e recomendações. Brasilia, 2011; 2ª Edção.

MONTEIRO, J. H.P. Manual de gerenciamento integrado de resíduos sólidos. Coordenação técnica Victor Zular Zveibil, Rio de Janeiro: IBAM, 2001

MORAES, Luiz Roberto Santos. Impacto na saúde do acondicionamento e da coleta dos resíduos sólidos domiciliares. In: Congresso Interamericano de Ingeniería Sanitaria y Ambiental, XXVI., 1998, Lima-Peru. Anais... Lima: AIDIS/APIS, 1998. 1 CD-ROM. 10p.

MORAES, Luiz Roberto Santos; LUZ, Lafayette Dantas da; SILVA, Bruno Jardim da Silva et al. Plano de Saneamento Ambiental para Vitória da Conquista: uma contribuição metodológica. In: Congresso Brasileiro de Engenharia Sanitária e Ambiental, 20., 1999, Rio de Janeiro. Anais... Rio de Janeiro: ABES, 1999a. 1 CDROM. p. 3442-3461

PRANDINI, F. L.; JARDIM, N. S.; D'ALMEIDA, M. L. Lixo Municipal: manual de gerenciamento integrado. São Paulo: Instituto de Pesquisas Tecnológicas (IPT), Compromisso Empresarial para Reciclagem(CEMPRE), 1995.

SILVA, L. Aterros sanitários são a melhor forma de destinação do lixo urbano. 2014. Disponível em:< http://www.cpt.com.br/cursos-meioambiente/artigos/aterros-sanitariossao-amelhor-forma-de-destinacao-do-lixo-urbano>. Acesso em: 01 abril. 2017. 